\title{
Поверхностные ансамбли на основе углеродных нанотрубок в пьезоэлектрическом иммуносенсоре для высокочувствительного определения рактопамина
}

\author{
Фарафонова О.В. ${ }^{1}$, Шукшина Е.И. ${ }^{1}$, Гражулене С.С. ${ }^{2}$, Ермолаева Т.Н. ${ }^{1}$ \\ ${ }^{1}$ Липечкий государственный технический университет, Липеиєк \\ ${ }^{2}$ Институт проблем технологии микроэлектроники и особо чистых материалов РАН, Черноголовка
}

Поступила в редакцию 5.04.2017 г.

\begin{abstract}
Изучены условия формирования распознающего слоя пьезоэлектрического сенсора на основе углеродных нанотрубок для высокочувствительного определения рактопамина в прямом формате иммуноанализа. Показано, что предварительная обработка углеродных нанотрубок концентрированными азотной и серной кислотами, а также активация карбоксильных групп карбодиимидным методом обеспечивают их прочное связывание с аминогруппами подложки на основе 2-меркаптоэтиламина и аминогруппами моноклональных антител к рактопамину, применяемых в качестве распознающих элементов сенсора. Установлены концентрации коллоидных растворов двух видов углеродных нанотрубок в диметилформамиде, обеспечивающие максимальные значения концентрационной чувствительности пьезоэлектрического сенсора при определении рактопамина. Диапазон определяемых содержаний рактопамина с помощью пьезоэлектрического сенсора составляет $\left(\right.$ нг $\left.\mathrm{cm}^{3}\right)$ 0.09-25, предел обнаружения 0.03.
\end{abstract}

Ключевые слова: пьезоэлектрический иммуносенсор, поверхностные ансамбли, моноклональные антитела, рактопамин, многостенные углеродные нанотрубки.

\section{Surface assemblies based on carbon nanotubes in a pie- zoelectric immunosensor for the highly sensitive deter- mination of ractopamine}

\author{
Farafonova O.V. ${ }^{1}$, Shukshina E.I. ${ }^{1}$, Grazhulene S.S. ${ }^{2}$, Ermolaeva T.N. ${ }^{1}$ \\ ${ }^{1}$ Lipetsk State Technical University, Lipetsk \\ ${ }^{2}$ Institute of Microelectronics and High Purity Materials, RAS technology, Chernogolovka
}

\begin{abstract}
The article proposes piezoelectric immunosensors based on surface ensembles of multi-walled carbon nanotubes (CNTs) for the determination in a direct format of an immunoassay of trace concentrations of ractopamine banned to be used in the Russian Federation as a feed additive to increase the productivity of livestock and a fat-burning agent for producing lean meat, Content on the health of consumers. The conditions for the formation of a recognition layer of a piezoelectric sensor based on carbon nanotubes for the highly sensitive determination of ractopamine in direct immunoassay format have been studied. The recognition layer was formed in several stages, including the modification of the sensor electrode by 2-mercaptoethylamine, the formation of ensembles based on multi-walled carbon nanotubes, and the immobilization of monoclonal antibodies to ractopamine on their surface. Preliminary treatment of carbon nanotubes with concentrated nitric and sulfuric acids, as well as activation of carboxyl groups by carbodiimide method, provides their strong binding to amino groups of a substrate based on 2-mercaptoethylamine and amino groups of monoclonal antibodies to ractopamine used as recognition elements of the sensor. The concentra-
\end{abstract}


tions of colloidal solutions of two types of carbon nanotubes in dimethylformamide are established, which ensure maximum values of the concentration sensitivity of the piezoelectric sensor when determining ractopamine. The increase in the concentration of CNTs at the stage of formation of the recognition layer leads to a simbatic change in the mass and thickness of the film coating, in the case of using colloidal solutions of CNTs with a concentration of $500 \mathrm{mg} / \mathrm{dm}^{3}$, the oscillation of the sensor oscillations is observed. The maximum value of Sc was noted when using solutions of CNT 1 and CNT-2 $100 \mathrm{mg} / \mathrm{dm}^{3}$ and $144 \mathrm{mg} / \mathrm{dm}^{3}, \mathrm{re}-$ spectively. The influence of concentration of monoclonal antibodies used in the immobilization stage was studied. The choice of the working concentration of antibodies was carried out at the maximum saturation of the sorption layer, with the concentration of monoclonal antibodies equal to $3.2 \mathrm{ng} / \mathrm{cm}^{3}$, the limiting density of the active binding sites on the surface of the sensor electrode is reached. Surface topography is estimated by atomic force microscopy, a significant increase in the average arithmetic roughness Ra of the CNT-based recognition layer as compared to the substrate based on 2-mercaptoethylamine is established, which indicates the possibility of placing more detectable molecules of monoclonal antibodies on the sensor electrode. The range of detectable contents of ractopamine by means of a piezoelectric sensor is $\left(\mathrm{ng} / \mathrm{cm}^{3}\right) 0.09-25$, the detection limit is 0.03 .

Keywords: piezoelectric immunosensor, surface ensembles, monoclonal antibodies, ractopamine, multiwalled carbon nanotubes.

\section{Введение}

В качестве аналитического сигнала пьезоэлектрического иммуносенсора выступает увеличение массы распознающего слоя при взаимодействии с определяемым соединением (прямой формат иммуноанализа) или антителами к нему (конкурентный формат иммуноанализа) [1]. Для получения распознающего слоя сенсора применяются, как правило, многостадийные способы, включающие модификацию поверхности электрода электрогенерированными пленками полимеров или самоорганизованными монослоями тиолов (силанов) [2-9], активацию бифункциональным реагентом и иммобилизацию антител или белковых конъюгатов аналита. Высокая адгезия слоя к поверхности металлического электрода сенсора обеспечивает сохранение постоянного значения массы при длительной эксплуатации в жидкости и определяется характером подложки, а чувствительность детектирования зависит от концентрации и пространственной доступности поверхностных «сайтов» связывания. Для повышения чувствительности пьезоэлектрического иммуносенсора при формировании распознающего слоя предложено использовать различные нанокомпозиты [10], применение которых, например, позволило проводить определение простатического специфического антигена на уровне пмоль/дм³ $[11]$.

Для детектирования низкомолекулярных соединений с помощью пьезоэлектрического сенсора обычно используется конкурентный формат иммуноанализа, недостатком которого является узкий линейный диапазон определяемых содержаний, необходимость синтеза и очистки гаптен-белкового коньюгата [12], иммобилизуемого на поверхности его электрода. Определение низкомолекулярных соединений в прямом формате требует применения распознающего слоя с высокой поверхностной концентрацией «сайтов» связывания, позволяющей проводить регистрацию присоединенной массы в ходе иммунохимической реакции на уровне $10^{-12}$ г. Увеличение удельной поверхности распознающего слоя возможно при применении многостенных углеродных нанотрубок.

Целью настоящего исследования являлась разработка пьезоэлектрического иммуносенсора на основе поверхностных ансамблей многостенных углеродных нанотрубок (УНТ) для определения в прямом формате иммуноанализа следовых концентраций рактопамина, запрещенного к использованию в РФ в качестве кормовой добавки для повышения продуктивности животноводства и жиросжигающего средства для получения постного мяса, вследствие негативного воздействия остаточных содержаний на здоровье потребителей. 


\section{Эксперимент}

Реагенты. Рактопамина гидрохлорид, моноклональные антитела к рактопамину («Sigma-Aldrich»); органические растворители - этанол, 96\%, ацетон, диметилформамид (ДМФ) («Quimica», Испания); неорганические реактивы: соляная ( $\rho=1.198$

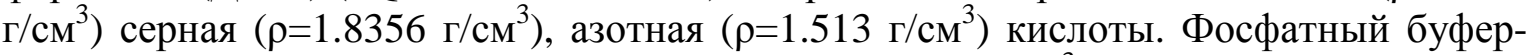
ный раствор (PBS, pH 7.2), готовили растворением в 1 дм $^{3}$ дистиллированной воды следующих реагентов (г): $\mathrm{NaCl}(8.0) ; \mathrm{KCl}(0.2) ; \mathrm{Na}_{2} \mathrm{HPO}_{4} \cdot 12 \mathrm{H}_{2} \mathrm{O}$ (2.9); $\mathrm{KH}_{2} \mathrm{PO}_{4}(0.2)$.

В работе использовали два вида многостенных углеродных нанотрубок, полученных в Институте проблем технологии микроэлектроники и особо чистых материалов РАН, (Черноголовка) методом каталитического пиролиза паров этанола при 400-550 ${ }^{\circ}$. В качестве катализаторов использовали железо (УНТ-1), а также никель (УНТ-2). В случае никеля предкатализатором служил нитрат никеля, который непосредственно перед осаждением УНТ термически разлагали до металла. При каталитическом разложении паров этанола УНТ осаждались на поверхности катализатора, который после синтеза отмывали кислотами. После отмывки катализатора образцы промывали дважды деионированной водой, высушивали, просеивали через сито [13].

Для формирования распознающего слоя использовали: 2-меркаптоэтиламин; $\mathrm{N}$-гидроксисукцинимид (NHS), N-этил-N'-(3-диметиламинопропил) карбодиимид гидрохлорид (EDAC) («Sigma-Aldrich»).

Подготовка углеродных нанотрубок. К 1 мг УНТ добавляли 2 см $^{3}$ смеси концентрированных азотной и серной кислот в соотношении 1:3 и обрабатывали ультразвуком в течение 1 ч при температуре $30-50{ }^{\circ} \mathrm{C}$, далее центрифугировали и промывали водой до нейтрального значения $\mathrm{pH}$ [14]. Полученную взвесь высушивали до постоянной массы. Углеродные нанотрубки растворяли в воде в следующих пропорциях: 1:2 (500 мг/дм $\left.{ }^{3}\right), 1: 5\left(200\right.$ мг/дм $\left.{ }^{3}\right), 1: 7\left(144\right.$ мг/дм $\left.{ }^{3}\right), 1: 10\left(100\right.$ мг/дм $\left.{ }^{3}\right), 1: 20$ (50 мг/дм $\left.{ }^{3}\right)$, добавляли диметилформамид для перевода в коллоидное состояние и обрабатывали ультразвуком (ультразвуковая ванна «ПСБ-Галас», Россия) в течение 40 мин. Активацию наночастиц осуществляли карбодиимидным методом [15]. Выбор растворов для активации УНТ осуществляли по значению оптической плотности с учетом реакции активных атомов азота с нингидрином: 2 мг нанотрубок помещали в микропробирку с $1 \mathrm{~cm}^{3} 5 \%$-ного спиртового раствора нингидрина и в течение 5 мин обрабатывали ультразвуком, затем реакционную смесь в течение 10 мин нагревали при $100^{\circ} \mathrm{C}$, после чего центрифугировали и измеряли оптическую плотность при длине волны 570 нм.

Подготовка сенсора и проведение измерений. В качестве сенсора использовали пьезокварцевые резонаторы АТ - среза с собственной частотой колебания 10 МГц с электродами диаметром 10 мм (ЗАО «ЭТНА», Россия). Исследования проводили на установке, описанной ранее [12], состоящей из схемы возбуждения, перистальтического насоса К-120 (Knauer, Германия), частотного модуля «ДиСкоп» («Бафика», Москва) и ПК.

Для формирования подложки на предварительно обезжиренную поверхность электрода сенсора наносили каплю 5\%-ого этанольного раствора 2-меркаптоэтиламина, высушивали при $80^{\circ} \mathrm{C}$ в сушильном шкафу в течение 20 мин, а затем на сенсор помещали 2 мкл карбоксилированных УНТ, проводили активацию с помощью EDAC (5 мг) и смеси EDAC (2.5 мг) и NHS (5 мг) и в течение 90 мин наносили 5 мкл антител к рактопамину, выдерживали 12 ч при $4^{\circ} \mathrm{C}$ во влажной камере, после чего распознающий слой промывали и высушивали. 
В качестве аналитического сигнала сенсора использовали уменьшение частоты колебаний сенсора $(\Delta \mathrm{f})$ при увеличении массы распознающего слоя $(\Delta \mathrm{m})$ за счет образования гетерогенного иммунокомплекса: $\Delta \mathrm{f}=\mathrm{k} \cdot \Delta \mathrm{m}$.

Качество полученных покрытий оценивали по следующим параметрам [5]:

- массе биослоя (мкг), рассчитанной по уравнению:

$$
\Delta m_{n л}=1,23 \cdot \Delta f^{\prime},
$$

- толщине распознающего слоя, нм

$$
\Delta h=0,043 \cdot \Delta f^{\prime},
$$

где $\Delta \mathrm{f}^{\prime}$ разность частот колебания сенсора до и после иммобилизации,

- числу устойчивых циклов измерений $\mathrm{N}$ (аналитический сигнал не снижается более чем на $5 \%$ ),

- концентрационной чувствительности $\left(\mathrm{S}_{\mathrm{c}}\right.$, Гц·см$\left.{ }^{3} / \mathrm{M \kappa}\right)$ сенсора, показывающей изменение частоты колебаний иммуносенсора:

$$
S_{c}=\frac{\Delta f}{c^{\prime}}
$$

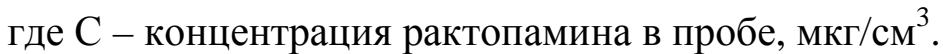

Изучение морфологии поверхности распознающего слоя осуществляли с помощью атомного силового микроскопа SOLVER P47-Pro (ЗАО «НанотехнологияМДТ», Зеленоград, Россия).

\section{Обсуждение результатов}

Распознающий биослой пьезоэлектрического иммуносенсора должен иметь хорошую адгезию к поверхности металлического электрода, что влияет на устойчивость его сигнала при многократном применении в жидких средах, высокую поверхностную концентрацию и равномерное расположение «сайтов» распознавания по всей площади электрода, минимальную масса и толщину. Изучены условия создания распознающего слоя пьезоэлектрического иммуносенсора для высокочувствительного определения рактопамина в прямом формате иммуноанализа. Формирование распознающего слоя осуществляли в несколько стадий, включающих модификацию электрода сенсора 2-меркаптоэтиламином, образование ансамблей на основе многостенных углеродных нанотрубок и иммобилизацию на их поверхности моноклональных антител к рактопамину (рис. 1).

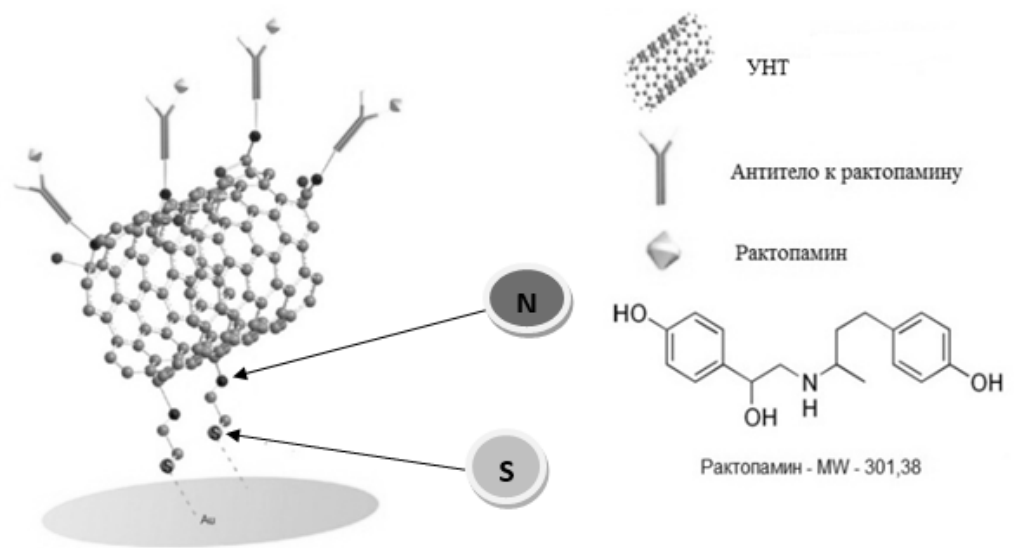

Рис. 1. Схема иммобилизации антител к рактопамину на подложке из 2-меркаптоэтиламина и УНТ

Для этого было необходимо изучить: 
- условия активации карбоксильных групп многостенных углеродных нанотрубок УНТ-1 и УНТ-2 для повышения эффективности связывания как с аминогруппами подложки, так и с моноклональными антителами к рактопамину;

- влияние концентрации коллоидных растворов УНТ и моноклональных антител на характеристики распознающего слоя сенсора;

- изменение морфологии поверхности распознающего слоя сенсора на основе углеродных нанотрубок;

- возможность пьезоэлектрического иммуносенсора для определения рактопамина в прямом формате иммуноанализа.

Ранее было установлено, что предварительная модификация золотого электрода пьезоэлектрического сенсора 2-меркаптоэтиламином, обеспечивающим высокую адгезию к поверхности золотого электрода за счет образования координационных связей между атомами серы и $\mathrm{Au}$, способствует формированию плотного и легкого покрытия с высокой концентрацией поверхностных аминогрупп [4]. Увеличение удельной поверхности сенсора может быть достигнуто за счет формирования ансамблей на основе многостенных углеродных нанотрубок, способствующих благодаря возникновению 3D граничного слоя существенному возрастанию его связывающей способности, что особенно важно при определении соединений с молекулярной массой<500 Da в прямом формате иммуноанализа. Для повышения устойчивости распознающего слоя предложено осуществлять ковалентное связывание УНТ с аминогруппами подложки и белковыми молекулами антител после их обработки смесью активных серной и азотной кислот, приводящей к образованию на их поверхности карбоксильных групп, и последующей активации последних карбодиимидным методом [17].

Выбор состава раствора для активации УНТ осуществляли с учетом оптической плотности, пропорциональной концентрации нингидрина, израсходованной на реакцию с активными атомами азота после обработки углеродных нанотрубок водным и спиртовым растворами EDAC, или EDAC/NHS в этиловом спирте. Эффективность активации оценивали по величине $S$, ммоль/г, показывающей удельное содержание активных атомов азота на поверхности УНТ (табл. 1), рассчитанной по методике, описанной в $[15,16]$. Более высокая концентрация активных групп азота отмечается при использовании EDAC/NHS для обоих типов углеродных нанотрубок.

Таблица 1. Удельное содержание активных атомов азота на поверхности УНТ $(\mathrm{n}=3 ; \mathrm{P}=0.95)$

\begin{tabular}{|c|c|c|c|}
\hline \multirow{2}{*}{ № } & \multirow{2}{*}{ Тип активации } & \multicolumn{2}{|c|}{ S, ммоль/г } \\
\cline { 3 - 4 } & & УНT-1 & УНT-2 \\
\hline 1 & EDAC/NHS (спирт) & 0.24 & 0.27 \\
\hline 2 & EDAC (водн) & 0.09 & 0.09 \\
\hline 3 & EDAC (спирт) & 0.11 & 0.13 \\
\hline
\end{tabular}

На характеристики распознающего слоя пьезоэлектрического сенсора также существенное влияние оказывает концентрация моноклональных антител, применяемая на стадии иммобилизации. Выбор рабочей концентрации антител осуществляли по максимуму насыщения сорбционного слоя (рис. 2). Таким образом, при применении на стадии иммобилизации концентрации моноклональных антител, рав-

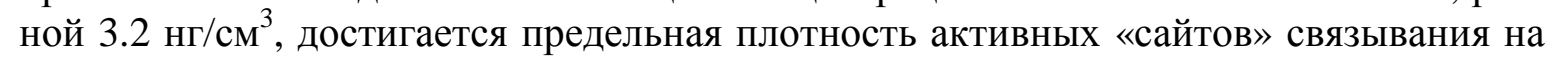
поверхности электрода сенсора. 


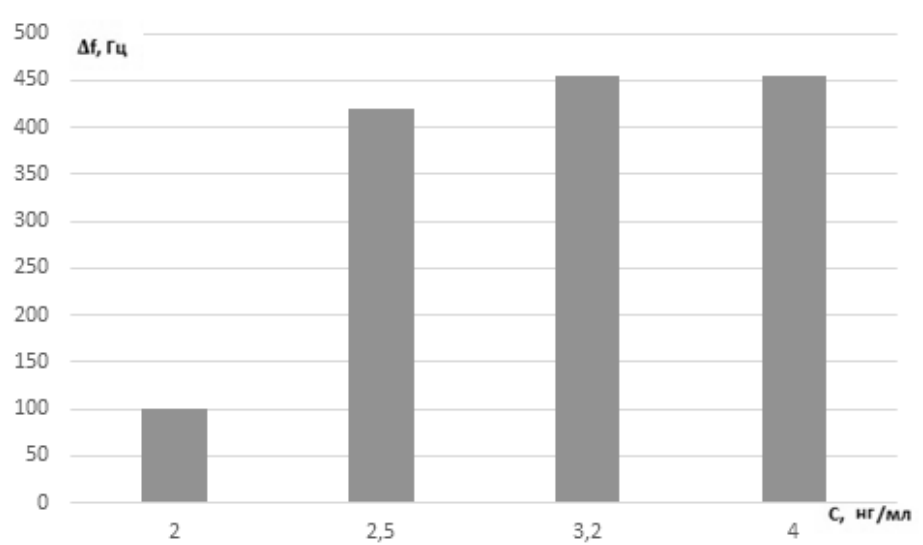

Рис. 2. Зависимость сигнала сенсора от концентрации антител

Для выбора концентрации УНТ, обеспечивающей максимальную удельную поверхность, измеряли аналитический сигнал сенсора при его контакте с раствором

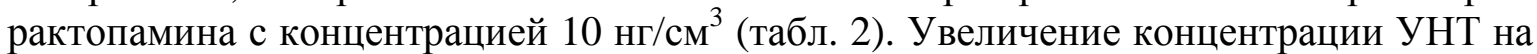
стадии формирования распознающего слоя приводит к симбатному изменению массы и толщины пленочного покрытия, в случае использования коллоидных растворов УНТ с концентрацией 500 мг/дм ${ }^{3}$ наблюдается срыв колебаний сенсора. Максимальное значение $\mathrm{S}_{\mathrm{c}}$ отмечено при использовании растворов УНТ 1 и УНТ-2 100 мг/дм ${ }^{3}$ и 144 мг/дм ${ }^{3}$ соответственно.

Таблица 2. Влияние концентрации УНТ на характеристики пьезоэлектрического сенсора для определения рактопамина $(\mathrm{P}=0.95 ; \mathrm{n}=5)$ (Сантител $\left.3.2 \mathrm{Hг} / \mathrm{cm}^{3}\right)$

\begin{tabular}{|c|c|c|c|c|}
\hline Вид УНТ & $\mathrm{C}, \mathrm{мг} / д \mathrm{M}^{3}$ & $\Delta \mathrm{m}, \mathrm{MКг}$ & $\Delta \mathrm{h}, \mathrm{HM}$ & 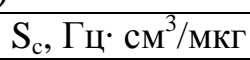 \\
\hline \multirow{5}{*}{ УНТ-1 } & 50 & 20.01 & 0.70 & 155 \\
\hline & 100 & 23.15 & 0.8 & 504 \\
\hline & 144 & 26.13 & 0.91 & 368 \\
\hline & 200 & 42.91 & 1.50 & 204 \\
\hline & 500 & - & - & - \\
\hline \multirow{5}{*}{ УНТ-2 } & 50 & 25.45 & 0.89 & 204 \\
\hline & 100 & 40.78 & 1.43 & 232 \\
\hline & 144 & 67.45 & 2.36 & 692 \\
\hline & 200 & 116.28 & 4.07 & 505 \\
\hline & 500 & - & - & - \\
\hline
\end{tabular}

При оценке топографии поверхности методом атомно силовой микроскопии установлено существенное увеличение средней арифметической шероховатости Ra распознающего слоя на основе УНТ по сравнению с подложкой на базе 2-меркаптоэтиламина (рис. 3), что свидетельствует о возможности размещения на электроде сенсора большего количества распознающих молекул моноклональных антител.

Пьезоэлектрические иммуносенсоры применены для определения рактопамина в модельных растворах в прямом формате анализа (табл. 3). Следует отметить более широкий диапазон определяемых содержаний по сравнению с конкурентным методом определения рактопамина и более низкий предел обнаружения [18]. Распознающий слой сенсора проявляет устойчивость в жидких средах, что позволяет осуществлять до 36-37 циклов измерения на одном покрытии. 

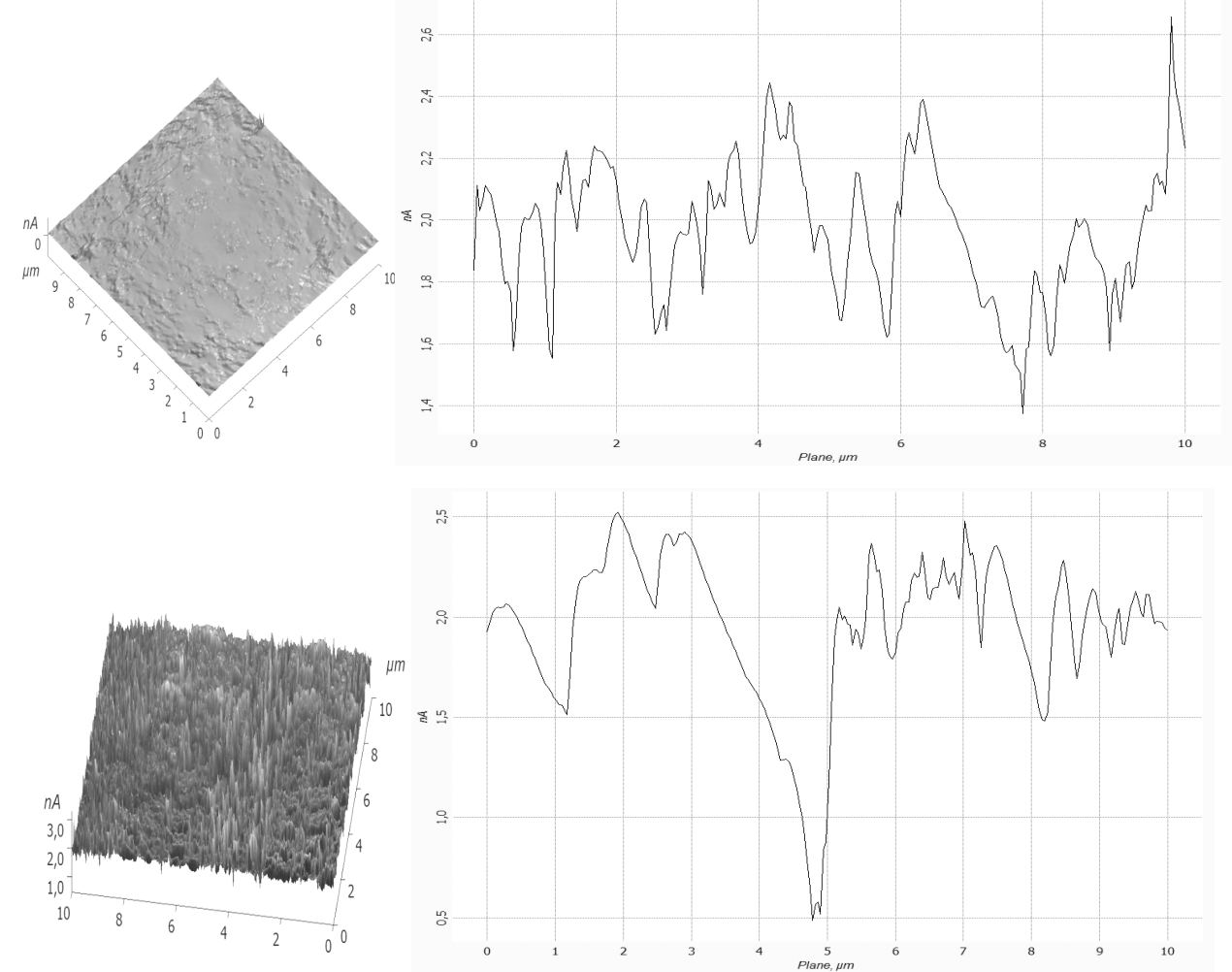

Рис. 3/ Морфология и профиль поверхности слоя 2-меркаптоэтиленамина до $\left(\mathrm{R}_{\mathrm{a}}=83 \mathrm{Hм}\right)$ и после $\left(\mathrm{R}_{\mathrm{a}}=331 \mathrm{Hм}\right)$ нанесения УНТ-2

Таблица 3. Метрологические характеристики определения рактопамина в прямом формате анализа $(\mathrm{P}=0.95 ; \mathrm{n}=3)$

\begin{tabular}{|c|c|c|c|c|c|}
\hline УНТ & $\begin{array}{c}\mathrm{C}_{\min } \\
\mathrm{нг} / \mathrm{cm}^{3}\end{array}$ & $\begin{array}{c}\text { Диапазон определяемых } \\
\text { содержаний, } \mathrm{Hг} / \mathrm{cm}^{3}\end{array}$ & $\begin{array}{c}\text { Уравнение градуировочно- } \\
\text { го графика }\end{array}$ & $\mathrm{R}^{2}$ & $\mathrm{~N}$ \\
\hline УНТ-1 & 0.04 & $0.1-22$ & $\mathrm{y}=4.9 \mathrm{x}+50.6$ & 0.99 & 36 \\
\hline УНТ-2 & 0.03 & $0.1-25$ & $\mathrm{y}=7.2 \mathrm{x}+86.4$ & 0.99 & 37 \\
\hline
\end{tabular}

При применении УНТ-1 и УНТ-2 сенсоры демонстрируют практически одинаковые $\mathrm{C}_{\min }$ и диапазоны определяемых содержаний. Однако в случае УНТ-2 отмечается более высокий коэффициент чувствительности при определении рактопамина, это связано с условиями синтеза на никелевом катализаторе.. Ранее установлено, что трубки, полученные данным способом, обладают максимальной способностью к модификации и, соответственно, максимальной сорбционной ёмкостью. Разработанные сенсоры могут быть рекомендованы для определения рактопамина в реальных объектах.

\section{Список литературы}

1. Blanca J., Munoz P., Morgado M., 4. Фарафонова О.В., Шихалиев Х.С., Mendez N. et al. // Anal. Chim. Acta. 2005. Vol. Ермолаева T.Н. // Современные проблемьl 529. pp. 199-205. науки и образования. 2012. № 6. С. 721.

2. Ермолаева Т.Н., Калмыкова Е.Н. // 5. Калмыкова Е.Н., Мелихова Е.В., Успехи химии. 2006. Т. 75. № 5. С. 445-459. Еремин С.А., Ермолаева Т.Н. //

3. Khan M. Z. H., Harkin-Jones E. // Cogent Антибиотики и химиотерапия. 2004. T. 49. Engineering. 2016. Vol. 3. pp. 1-18. № 1. C. 8-13. http://dx.doi.org/10.1080/23311916.2016.11700 97 
6. Blanca J., Munoz P., Morgado M., Mendez N. et al. // Anal. Chim. Acta. 2005. Vol. 529. pp. $199-205$.

7. Elliott C.T., Thompson C.S., Arts C.J., Crooks S.R. // Analyst. 1998. Vol. 123. pp 1103-1107.

8. Turberg M.E., Rodewald J.M., Coleman M.R. // J. Chromatogr. Biomed. Appl. 1996. Vol. 675. No 2. pp. 279-285.

9. Wang J.P., Li X.W., Zhang W., Shen J.Z. // Chromatographia. 2006. Vol. 64. pp. 613617.

10. Белякова Н.В, Нечаева Л.С., Бутырская Е.В., Шапошник В.А. и др. // Сорбичинные и хроматографические прочессы. 2016. Т. 16. № 4. C. 526-532.

11. Chen H., Huang J., Fam D.W.H., Tok A.I.Y. // Bioengineering. 2016. Vol. 3. No 23. pp. 1-10. doi:10.3390/bioengineering3040023

12. Ермолаева Т.Н., Воронежцева О.В. // Сорбиионные и хроматографические проиессы. 2011. T. 1. № 1. C. 68-76.

\section{References}

1. Blanca J., Munoz P., Morgado M., Mendez $\mathrm{N}$ et al., Anal. Chim. Acta. 2005, Vol. 529, pp. 199-205.

2. Ermolaeva T.N., Kalmykova E.N., Uspekhi khimii, 2006, Vol. 75, No 5, pp. 445-459.

3. Khan M.Z.H., Harkin-Jones E., Cogent Engineering, 2016, Vol. 3, pp. 1-8. http://dx.doi.org/10.1080/23311916.2016.11700 97

4. Farafonova O.V., Shikhaliev Kh.S., Ermolaeva T.N., Sovremennye problemy nauki i obrazovaniya, 2012, No 6, pp. 721.

5. Kalmykova E.N., Melikhova E.V., Eremin S.A., Ermolaeva T.N., Antibiotiki i khimioterapiya, 2004, Vol. 49, No 1, pp. 8.

6. Blanca J., Munoz P., Morgado M., Mendez N. et al., Anal. Chim. Acta., 2005, Vol. 529, pp. 199-205.

7. Elliott C.T., Thompson C.S., Arts C.J., Crooks S.R., Analyst, 1998, Vol. 123, pp 11031107.

8. Turberg M.E., Rodewald J.M., Coleman M.R., J. Chromatogr. Biomed. Appl., 1996, Vol. 675, No 2, pp. 279-285.

9. Wang J.P., Li X.W., Zhang W., Shen J.Z., Chromatographia, 2006, Vol. 64, pp. 613-617.

10.Belyakova N.V, Nechaeva L.S., Butyrskaya E.V., Shaposhnik V.A. et al., Sorbtsionnye
13. Гражулене С.С., Редькин А.Н., Телегин Г.Ф. // Журнал аналитической химии. 2012. Т. 67. № 5. С. 479-484.

14. Варламова Р.М., Медянцева Э.П., Хамидуллина Р.Р., Будников Г.К. // Учен. зап. Казан. ун-та. Сер. Естеств. науки. 2016. Т. 158. кн. 3. С. 351-368.

15. Palaniappana Al., Goha W.H., Yildiza U.H., Swarnalathab B. et al. // Sensors and Actuators B. 2012. Vol. 161. pp 689-696.

16. Ahammad A.J.S., Lee J-J., Rahman Md.A. // Sensors. 2009. Vol. 9. pp 2289-2319. doi:10.3390/s90402289.

17. Gromov A., Dittmer S., Svensson J., Nerushev O. et al. // J. Mater. Chem. 2005. Vol. 15. No 15. pp. 3334-3339.

18. Васильев С.В., Попова М.В., Фарафонова О.В., Карасева Н.А. и др. // Современные проблемы науки и образования. 2014. № 1. C. 444.

i khromatograficheskie protsessy, 2016, Vol. 16, No 4, pp. 526-532.

11. Chen H., Huang J., Fam D.W.H., Tok A.I.Y., Bioengineering, 2016, Vol. 3, No 23, pp. 1-10. doi:10.3390/bioengineering 3040023

12.Ermolaeva T.N., Voronezhtseva O.V., Sorbtsionnye i khromatograficheskie protsessy, 2011, Vol. 1, No 1, pp. 68-76.

13. Grazhulene S.S., Red'kin A.N., Telegin G.F., Zhurnal analiticheskoi khimii, 2012, Vol. 67, No 5, pp. 479-484.

14. Varlamova R.M., Medyantseva E.P., Khamidullina R.R., Budnikov G.K., Uchen. zap. Kazan. un-ta. Ser. Estestv. nauki., 2016, Vol. 158, kn. 3, pp. 351-368.

15.Palaniappana Al., Goha W.H., Yildiza U.H., Swarnalathab B. et al., Sensors and Actuators B,2012, Vol. 161, pp 689-696.

16. Ahammad A.J.S., Lee J-J., Rahman Md.A., Sensors, 2009, Vol. 9, pp 2289-2319. doi:10.3390/s90402289.

17. Gromov A., Dittmer S., Svensson J., Nerushev O. t al, J. Mater. Chem., 2005, Vol. 15, No 15, pp. 3334-3339.

18. Vasil'ev S.V., Popova M.V., Farafonova O.V., Karaseva N.A. et al., Sovremennye problemy nauki i obrazovaniya, 2014, No 1, pp. 444. 
Ермолаева Татьяна Николаевна - профессор кафедры химии, д.х.н., Липецкий государственный технический университет, Липецк

Гражулене Светлана Степановна - главный научный сотрудник, д. х. н., Институт проблем технологии микроэлектроники и особочистых материалов РАН, Черниголовка

Фарафонова Ольга Вячеславовна - доцент кафедры химии, к.х.н., Липецкий государственный технический университет, Липецк

Шукшина Евгения Ивановна - аспирант кафедры химии, Липецкий государственный технический университет, Липецк.
Ermolaeva Tatyana N. - prof., grand Ph.D (chemistry), department of chemistry, Lipetsk State Technical University, Lipetsk, e-mail: etn@stu.lipetsk.ru

Grazhulene Svetlana S. - chief researcher, grand Ph.D (chemistry), Institute of Microelectronics Technology and High-Purity Materials, Russian Academy of Sciences, Chernigolovka, e-mail: grazhule@impthpm.ac.ru

Farafonova Olga V. - associate prof., Ph.D. (chemistry), department of chemistry, Lipetsk State Technical University, Lipetsk, e-mail: farafonova.ov@mail.ru

Shukshina Evgenia I. - the postgraduate student, department of chemistry, Lipetsk State Technical University, Lipetsk. 